\title{
Modeling and Controller Design of a Bidirectional Resonant Converter Battery Charger
}

\author{
ZAKARIYA M. DALALA ${ }^{1}$, (Member, IEEE), ZAKA ULLAH ZAHID², \\ OSAMA S. SAADEH ${ }^{\circledR 1}$, (Member, IEEE), AND JIH-SHENG LAI ${ }^{\circledR 3}$, (Fellow, IEEE) \\ ${ }^{1}$ Department of Energy Engineering, German Jordanian University, Amman 11180, Jordan \\ ${ }^{2}$ Department of Electrical Engineering, University of Engineering and Technology at Peshawar, Peshawar 25000, Pakistan \\ ${ }^{3}$ Department of Electrical and Computer Engineering, Virginia Tech, Blacksburg, VA 24061, USA \\ Corresponding author: Zakariya M. Dalala (Zakariya.Dalalah@gju.edu.jo)
}

\begin{abstract}
In this paper, a controller design methodology is proposed for a CLLLC-type bidirectional resonant converter. The soft switching of all devices in this topology and the very high operating frequency lead to increased overall system efficiency. However, the dynamic nature of this converter is highly dependent on loading conditions, which proves challenging when designing the voltage and current closed-loop controllers. System instability is mainly due to the high-Q resonant peaking, which is observed in the open-loop bode-plots. In this paper, the controller design methodology is proposed, which accounts for the dynamics behavior due to load variations. The controller stability will be evaluated against the entire range of operating switching frequency. Both battery charging and regeneration modes will be described and analyzed. The focal contribution of this paper will focus on defining the worst operating scenarios for the converter using system-level modeling and analysis. In addition, the controller will be defined based on these operating points. To validate and verify the controller design methodology proposed, a $3.5-\mathrm{kW}$ converter is designed with the appropriate output voltage and current loop controllers. The step response verified a stable system designed and thus proving the proposed controller design methodology.
\end{abstract}

INDEX TERMS DC-DC power converters, bidirectional power flow, resonant converters, control design, battery charger, closed-loop systems.

\section{INTRODUCTION}

Electric vehicles (EVs) have recently become increasingly popular, and penetration levels dramatically increased, mainly due to the many advancements in enabling technological aspects of manufacturing, resulting in greener and more reliable EVs [1]. EV technology development compliments the efforts being exerted on techniques to minimize vehicle fuel consumption, ranging from Eco-driving education to advanced engine control techniques [2], [3], and even advanced efforts were proposed on cyber-physical predictive control schemes to minimize vehicle fuel consumption [4].

EVs are considered green when powered from renewables, which is the main theme of new infrastructure support installations. The energy storage system (ESS) is key element to EVs, and usually it defines the capabilities of the EV [5]. Defining and optimizing the ESS continues to be of huge interest to researchers and manufacturers. Lithium-ion batteries represent the main choice thus far due to its advantages in terms of energy density and durability [6]. Hybridizing options with super-capacitors and fuel cells were investigated and reported as well to enhance the operational characteristics and minimize the ESS sizing [7]. Accompanying energy and power management controllers and algorithms were proposed to regulate and facilitate the hybrid systems [8]-[11].

As vital as it is for the ESS, charging technologies are of utmost importance in this regard and are in the focus of this work. On-board EV battery chargers can be either conductive [12]-[20] or inductive [20]-[27]. A front-end stage is essential for any on-board charger, in addition to the required regulating dc-dc power stage that manages the bidirectional energy transfer between the battery and the EV. A wide range selection of dc-dc converters have been adapted for EV battery management systems. Due to their higher efficiency and performance, resonant converters have become the topologies of choice. In addition to that, resonant converters have higher operating switching frequencies that are enabled by advanced semiconductor switches industry [12]-[19], [25]-[28]. One of the most appealing features of resonant converters is the ability to implement soft-switching in all switches, which results in the minimization of switching 
energy losses, in addition to reduced electromagnetic interference.

Control implementation in resonant converters' topologies is completely different from the traditional PWM converters wherein the output filter's cutoff frequency is much lower than that of the switching frequency (usually a ratio of 10 is used). In PWM converters, different modeling methods such as state-space averaging [29], [30] and PWM switch model [31]-[33] techniques where they are utilized to formulate the average converter model over one switching period to capture the dynamic behavior of the converter. These methods cannot be directly used in resonant converters' dynamic modeling since the switching frequency is close to the tank circuit resonant frequency. Several methods have been proposed for the derivation of the small-signal models of resonant converters in literature [34]-[41]. However, most of these methods are too complex [34], [35] or not accurate enough [36]-[40]. The Generalized State-Space Averaging (GSSA) method [42], [43] and the envelope modeling method [44] are tools used to predict the dynamics of resonant converters. These techniques are not suitable for higher order converters, as they become very complex and less accurate. The Extended Describing Functions (EDF) is another timedomain and frequency-domain analysis modeling technique, which uses multivariable describing functions to approximate the non-linear terms, [41], [45]-[48]. This method is accurate and not as complex. Circuit simulation softwares and CAD tools can be used as well to generate the open-loop bode-plots to design compensators [49], [25].

In this paper, a controller design methodology for a $C L L L C$-type resonant converter is proposed, which is valid for a wide range of input and output voltages. As the dynamics of resonant converters change due to changing loading conditions, it is essential that the controller is properly designed, otherwise, at some operating points, the closedloop system might become unstable. Defining the worst case operating condition scenario is the main challenge when targeting a globally stable controller design. Frequency response will be used to define the worst case operating scenario and to design the stable controller. Both, voltage and current loops will be designed and the stability guarantee margins will be shown. The steady-state and the small-signal models derivation for the IPT system [47] are applicable for this converter as well. Hardware prototype for a $3.5 \mathrm{~kW}$ system is designed and built to validate the design methodology proposed in this manuscript, and experimental test results prove the effectiveness of the proposed approach. This work has been presented initially at [50] and an extension and detailed analysis is included here as well.

\section{FUNDAMENTAL ANALYSIS AND CONVERTER MODELING}

\section{A. CONVERTER POWER STAGE}

The CLLLC resonant converter is shown in Fig. 1. The converter is capable of bidirectional operation. The high

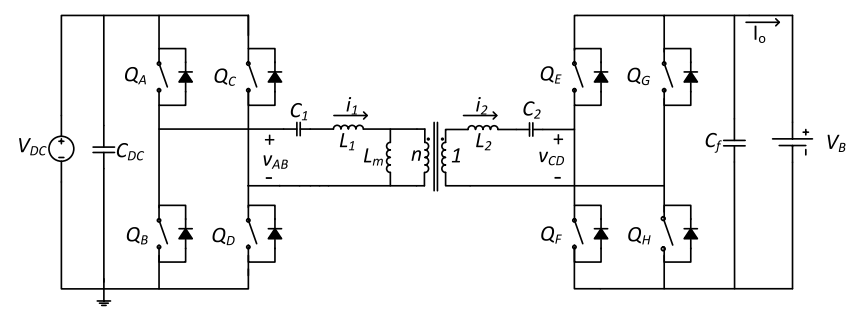

FIGURE 1. Bidirectional resonant converter circuit topology.

frequency signal generated by the primary stage is filtered by the resonant tank circuit to only pass the fundamental component to the secondary side, where it is rectified before being supplied to the load. The transformer provides galvanic isolation, and turns ration may be set to enhance the conversion ratio if required.

\section{B. STEADY-STATE AND SMALL-SIGNAL MODELS}

Fig. 2 shows the equivalent circuit representation for the CLLLC converter with the battery load represented by a dynamic resistance [47]. The dynamic analysis shown in [47] will be applied here. The large-signal, steady-state and smallsignal models for the IPT system are formulated based on Extended Describing Functions (EDF). This basically elevates the harmonic balance to derive the system dynamics. Assuming that all state variables are described with sinusoidal functions as can be excluded from Fourier series analysis, harmonic balance can be applied at the fundamental frequency $\omega_{s}$. (1) to (8) describe the derived model.

$$
\begin{aligned}
v_{A B} & =\frac{4 V_{D C}}{\pi} \cdot \sin \left(\omega_{s} t\right) \\
v_{C D} & =\operatorname{sign}\left(i_{2}\right) \cdot V_{o} \\
i_{\text {rect }} & =\left|i_{2}\right|
\end{aligned}
$$

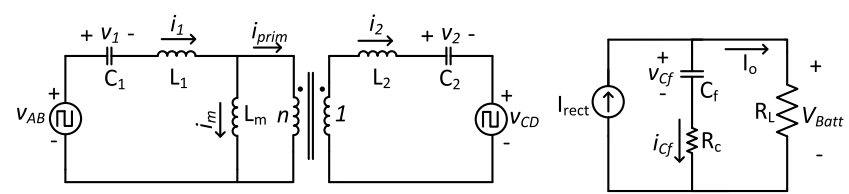

FIGURE 2. Equivalent circuit for the CLLLC converter.

The voltages and currents can be approximated at the fundamental frequency using Fourier series analysis as follows:

$$
\begin{aligned}
& i_{1}=I_{1 s} \cdot \sin \left(\omega_{s} t\right)+I_{1 c} \cdot \cos \left(\omega_{s} t\right) \\
& v_{1}=V_{1 s} \cdot \sin \left(\omega_{s} t\right)+V_{1 c} \cdot \cos \left(\omega_{s} t\right) \\
& i_{2}=I_{2 s} \cdot \sin \left(\omega_{s} t\right)+I_{2 c} \cdot \cos \left(\omega_{s} t\right) \\
& v_{2}=V_{2 s} \cdot \sin \left(\omega_{s} t\right)+V_{2 c} \cdot \cos \left(\omega_{s} t\right)
\end{aligned}
$$

The steady-state equations are derived as (8) and (9), as shown at the bottom of the next page. 
The output current and voltage at the steady-state can be calculated as in (10) and (11).

$$
\begin{aligned}
V_{o} & =V_{C f}=\frac{2}{\pi} I_{p k} R_{L} \\
I_{o} & =\frac{V_{o}}{R_{L}}=\frac{2}{\pi} I_{p k} \\
I_{p k}^{2} & =\left(I_{2 s}\right)^{2}+\left(I_{2 c}\right)^{2}
\end{aligned}
$$

The converter output voltage and current versus the operating switching frequency curves are plotted using (10) and (11). The linearized small-signal model derived from (8) is (12) and (13), as shown at the bottom of the next page.

The variables $K_{1} \sim K_{22}$ are listed in the appendix. The $(\wedge)$ stands for the small signal perturbation from the linearization process. The Transfer functions can be found using Equations (12) and (13) as following:

$$
G_{p}(s)=C \cdot[s I-A]^{-1} \cdot B=\left[\begin{array}{lll}
G_{v f}(s) & G_{v v g}(s) & G_{v d}(s)
\end{array}\right]
$$

Both, the frequency and the phase-shift control are included in the small-signal model in (12) and (13). With the phase-shift control, the ZVS range for the primary side switches depend on the series leakage inductance. Thus, ZVS operation cannot be guaranteed at all load conditions if phase shift control is adapted. If frequency control is utilized, then ZVS can be guaranteed at all line and load conditions if the primary-side current lags the primary-side bridge voltage. Therefore, frequency control will be adapted here.

\section{SMALL-SIGNAL MODEL VERIFICATION}

The transfer functions can be deduced from (14), where they are used to design the closed loop controllers of the current and voltage, given that the control input is the frequency. So, the control-to-output current transfer function, $G_{i f}(s)$ and the control-to-output voltage transfer function, $G_{v f}(s)$ are derived in both $B C M$ and RM. In Fig. 3, the voltage gain is shown versus the switching frequency for the converter with a resistive load $R_{L}$ of $45 \Omega$. The remaining circuit parameters are listed below:
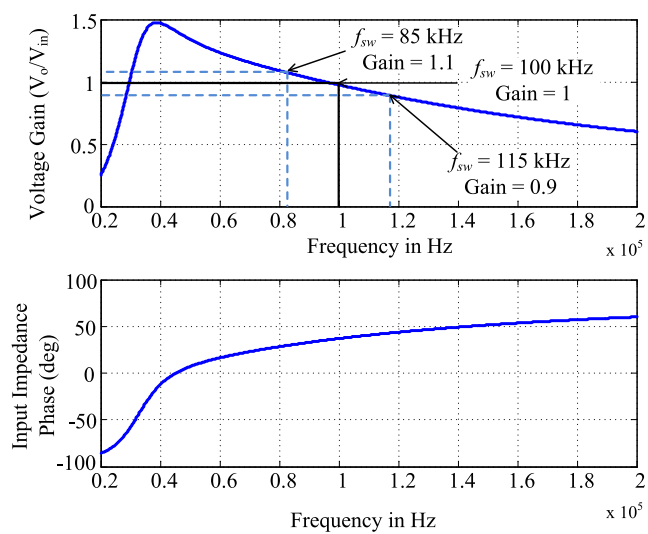

FIGURE 3. Voltage gain versus switching frequency.

$$
\begin{aligned}
& B_{s t}=A_{s t} \cdot X_{s t} \\
& A_{s t}=\left[\begin{array}{cccccccc}
1 & \frac{L_{e q 2}}{L_{e q m}} & 0 & \frac{L_{e q 2} R_{e}}{L_{e q m}} & 0 & 0 & -\Omega_{s} L_{e q 2} & 0 \\
1 & \frac{L_{e q m}}{L_{e q 1}} & 0 & \frac{L_{e q m} R_{e}}{L_{e q 1}} & 0 & 0 & 0 & -\Omega_{s} L_{e q m} \\
0 & 0 & 1 & 0 & \Omega_{s} C_{1} & 0 & 0 & 0 \\
0 & 0 & 0 & 1 & 0 & \Omega_{s} C_{2} & 0 & 0 \\
0 & 0 & \Omega_{s} L_{e q 2} & 0 & 1 & \frac{L_{e q 2}}{L_{e q m}} & 0 & \frac{L_{e q 2} R_{e}}{L_{e q m}} \\
0 & 0 & 0 & \Omega_{s} L_{e q m} & 1 & \frac{L_{e q m}}{L_{e q 1}} & 0 & \frac{L_{e q m} R_{e}}{L_{e q 1}} \\
-\Omega_{s} C_{1} & 0 & 0 & 0 & 0 & 0 & 1 & 0 \\
0 & -\Omega_{s} C_{2} & 0 & 0 & 0 & 0 & 0 & 1
\end{array}\right] \\
& B_{s t}=\left[\begin{array}{llllllll}
V_{e} & V_{e} & 0 & 0 & 0 & 0 & 0 & 0
\end{array}\right]^{T} \\
& X_{s t}=\left[\begin{array}{llllllll}
V_{1 s} & V_{2 s} & I_{1 s} & I_{2 s} & V_{1 c} & V_{2 c} & I_{1 c} & I_{2 c}
\end{array}\right]^{T} \\
& V_{e}=\frac{4}{\pi} \cdot V_{D C}, \quad R_{e}=\frac{8}{\pi^{2}} R_{L}, \Omega_{s}=2 \cdot \pi \cdot f_{s w} \\
& L_{e q 1}=\frac{n^{2} L_{11} L_{22}-L_{m}^{2}}{n^{2} L_{11}}, \quad L_{e q 2}=\frac{n^{2} L_{11} L_{22}-L_{m}^{2}}{n^{2} L_{22}} \\
& L_{e q m}=\frac{n^{2} L_{11} L_{22}-L_{m}^{2}}{n L_{m}} . \\
& X_{s t}=A_{s t}^{-1} \cdot B_{s t}
\end{aligned}
$$


TABLE 1. Converter Circuit Parameters

\begin{tabular}{|c|c|c|c|c|c|}
\hline$\left(L_{1}, L_{2}\right)$ & $\left(L_{m}\right)$ & $\left(C_{1}\right)$ & $\left(C_{2}\right)$ & $(n)$ & $\left(C_{f}\right)$ \\
\hline $20 \mu H$ & $100 \mu H$ & $136 n F$ & $200 n F$ & 1 & $30 \mu F$ \\
\hline
\end{tabular}

The converter gain is unity at the primary side series resonant frequency $f_{\text {ser }}$ of $100 \mathrm{kHz}$, boost operation for $f_{s}>f_{\text {ser }}$, and buck operation for $f_{s}<f_{\text {ser }}$. Since, the voltage-controlled oscillator (VCO) is implemented in the DSP, it cannot be perturbed and hence, it is not possible to measure the open-loop
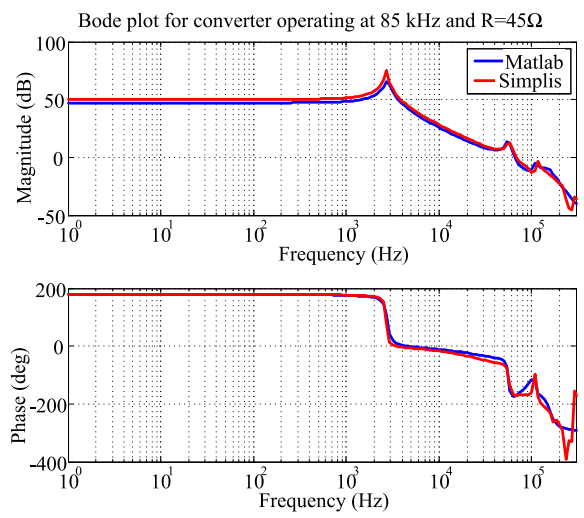

FIGURE 4. Open-loop of $G_{v f}(s)$, for the converter operating at $f_{s}=80 \mathrm{kHz}$.
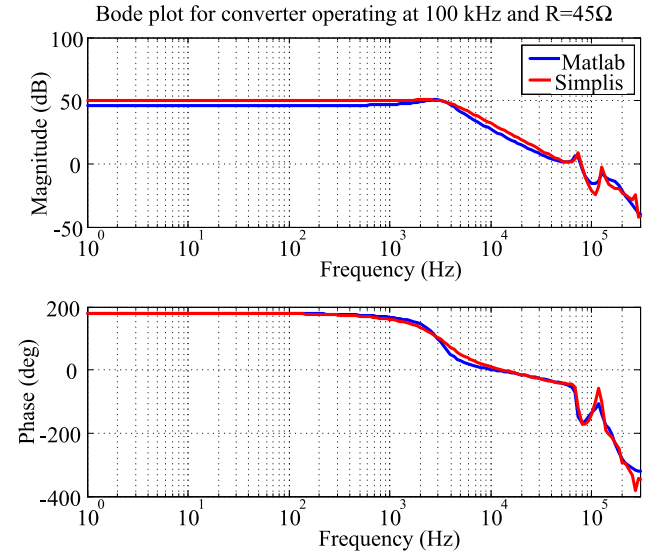

FIGURE 5. $G_{v f}(s)$ of the converter at unity gain operation at $f_{S}=100 \mathrm{kHz}$. transfer function. However, circuit simulation software can be used to carry the AC analysis [22].The open-loop bode-plot will be compared with the simulation results using SIMPLIS to validate the model in (12-13) as show in Figs. 4-6, where the MatLab generated plots are the predicted responses shown in (12-13). It is clearly shown that the model in (12-13) is validated at different switching frequencies.

III. WORST-CASE SCENARIOS FOR CONTROLLER DESIGN The small-signal model in (12) and (13) will be used to design both the voltage and current controllers for

$$
\begin{aligned}
& \frac{d}{d t} \hat{x}=A \cdot \hat{x}+B \cdot \hat{u} \\
& \hat{y}=C \cdot \hat{x} \\
& A=\left[\begin{array}{ccccccccc}
0 & \Omega_{s} & -K_{1} & K_{2} & \frac{-1}{L_{e q 2}} & 0 & \frac{-1}{L_{e q m}} & 0 & -K_{3} \\
-\Omega_{s} & 0 & K_{11} & -K_{12} & 0 & \frac{-1}{L_{e q 2}} & 0 & \frac{-1}{L_{e q m}} & -K_{13} \\
0 & 0 & -K_{6} & \Omega_{s}+K_{7} & \frac{-1}{L_{e q m}} & 0 & \frac{-1}{L_{e q 1}} & 0 & -K_{8} \\
0 & 0 & -\Omega_{s}+K_{14} & -K_{15} & 0 & \frac{-1}{L_{e q m}} & 0 & \frac{-1}{L_{e q 1}} & -K_{16} \\
\frac{1}{C_{1}} & 0 & 0 & 0 & 0 & \Omega_{s} & 0 & 0 & 0 \\
0 & \frac{1}{C_{1}} & 0 & 0 & -\Omega_{s} & 0 & 0 & 0 & 0 \\
0 & 0 & \frac{1}{C_{2}} & 0 & 0 & 0 & 0 & \Omega_{s} & 0 \\
0 & 0 & 0 & \frac{1}{C_{2}} & 0 & 0 & -\Omega_{s} & 0 & 0 \\
0 & 0 & K_{17} & K_{18} & 0 & 0 & 0 & 0 & -K_{19}
\end{array}\right] \\
& B=\left[\begin{array}{ccccccccc}
\omega_{o} I_{1 c} & -\omega_{o} I_{1 s} & \omega_{o} I_{2 c} & -\omega_{o} I_{2 s} & \omega_{o} V_{1 c} & -\omega_{o} V_{1 s} & \omega_{o} V_{2 c} & -\omega_{o} V_{2 s} & 0 \\
K_{4} & 0 & K_{9} & 0 & 0 & 0 & 0 & 0 & 0 \\
K_{5} & 0 & K_{10} & 0 & 0 & 0 & 0 & 0 & 0
\end{array}\right]^{T} \\
& C=\left[\begin{array}{lllllllll}
0 & 0 & K_{20} & K_{21} & 0 & 0 & 0 & 0 & K_{22}
\end{array}\right] \\
& \widehat{x}=\left[\begin{array}{lllllllll}
\widehat{i_{1 s}} & \widehat{i_{1 c}} & \widehat{i_{2 s}} & \widehat{i_{2 c}} & \widehat{v_{1 s}} & \widehat{v_{1 c}} & \widehat{v_{2 s} s} & \widehat{v_{2 c}} & \widehat{v_{C f}}
\end{array}\right]^{T} \\
& \widehat{u}=\left[\begin{array}{lll}
\widehat{\omega_{n}} & \widehat{v_{g}} & \widehat{d}
\end{array}\right]^{T}, \quad \widehat{y}=\widehat{v_{o}}, \omega_{o}=\frac{1}{\sqrt{L_{1} C_{1}}}
\end{aligned}
$$



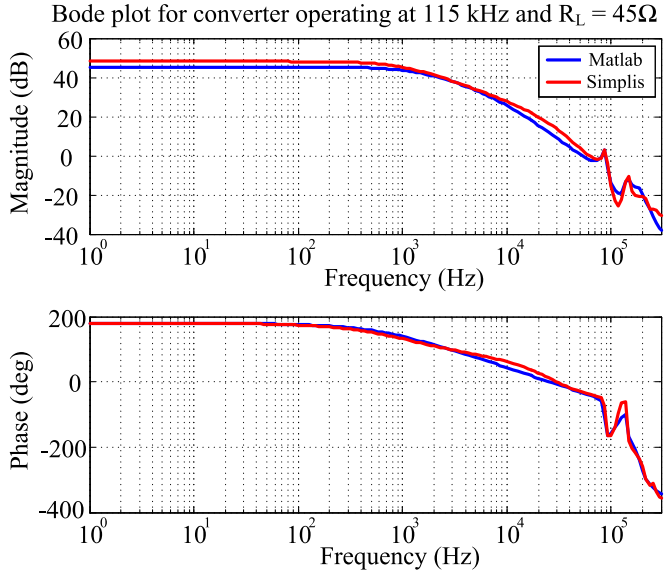

FIGURE 6. Bode plot of $G_{v f}(s)$ in the buck mode at $f_{s}=115 \mathrm{kHz}$.

TABLE 2. Converter Design Parameters

\begin{tabular}{cccc}
\hline Component & Value & Component & Value \\
\hline$V_{D C}$ & $400 \mathrm{~V}$ & $C_{D C}$ & $1.8 \mathrm{mF}$ \\
$L_{l}, L_{2}$ & $20 \mu \mathrm{H}$ & $L_{m}$ & $100 \mu \mathrm{H}$ \\
$C_{l}$ & $136 \mathrm{nF}$ & $C_{2}$ & $200 \mathrm{nF}$ \\
$C_{f}$ & $30 \mu \mathrm{F}$ & $V_{\text {Batt }-(V)}$ & $250 \sim 450$ \\
$C_{l}$ & $136 \mathrm{nF}$ & $C_{f}$ & $30 \mu \mathrm{F}$ \\
\hline
\end{tabular}

a bidirectional $3.5 \mathrm{~kW}$ resonant converter. The design parameters are listed in Table (2). The system dynamics depend on the operating point, which rapidly varies as the battery voltage changes. To design a globally stable controller for all operating points, the worst case operating conditions must be defined and designed for, which by itself, is not an easy task.

In $B C M$, constant current and constant voltage modes are both needed depending on the battery state of charge. In the $R M$, the converter only operates in the constant voltage mode with DC bus voltage regulation for a wide range of battery voltage.

The first step in the controller design process is to determine the equivalent load resistance. The operating switching frequency range then needs to be defined. These information allow for the definition of the controller worst-case scenario.

To determine the equivalent load resistance, $R_{L}$, Fig. 7 is used. The equivalent load resistance during $B C M\left(R_{L}=\frac{V_{\text {Batt }}}{I_{\text {Batt }}}\right)$ and during $R M\left(R_{L}=\frac{V_{D C}^{2}}{P_{o}}=\frac{V_{D C}}{I_{D C}}\right)$. The output voltage and current at the steady-state and at

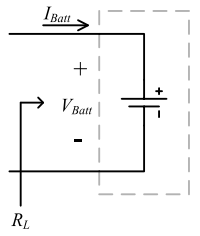

(a)

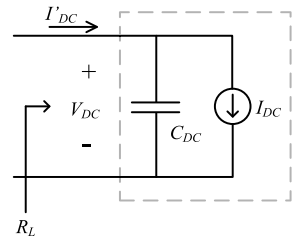

(b)
FIGURE 7. Converter equivalent output load resistance for $B C M$ and in the $R M$. (a) $R_{L}$ during the $B C M$. (b) $R_{L}$ during the $R M$. different load conditions are plotted vs. the operating switching frequency using (10) - (11) in order to determine the operating frequency range. It is important that the gain curves be monotonic at different load conditions for proper PID controller operation. Therefore, it is essential to plot these gain curves at all load conditions while checking the slope of the curves. This is achieved using 3-D plots (output current or voltage vs. $R_{L}$ vs. the switching frequency) over the entire operating switching frequency and load resistance defined ranges.

As mentioned earlier, the converter operating point move during the charging and discharging process. The zerocrossing and low-frequency gain of the open-loop bode-plot also change as the operating point changes. The worst-case is found by plotting the open-loop bode-plot at the operating switching frequencies and load resistances.

\section{A. BCM CURRENT LOOP CONTROLLER WORST-CASE OPERATING CONDITIONS}

The range of the equivalent load resistance $R_{L}$ depends on the charging profile which is defined as shown in Fig. 8. The charging power is maintained at $3.5 \mathrm{~kW}$. During constant current mode:

$$
R_{L_{-} I}=\frac{V_{\text {Batt }}}{I_{\text {Batt }}}=\frac{250 \mathrm{~V}}{10 \mathrm{~A}} \sim \frac{450 \mathrm{~V}}{7.5 \mathrm{~A}}=25 \Omega \sim 60 \Omega .
$$

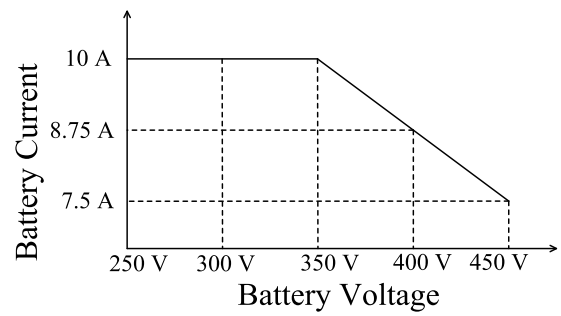

FIGURE 8. Battery current vs. voltage for the converter operating in the $B C M$.

During nominal operating conditions, battery voltage and current are $350 \mathrm{~V}$ and $10 \mathrm{~A}$, resulting in a nominal load resistance of $R_{L_{-} \text {Inom }}=35 \Omega$. The operating frequency range is determined by plotting the output current under steady-state conditions against the converter operating switching frequency at different load conditions. Fig. 9, shows the steady-state output current vs. the operating switching frequency for $R_{L-I_{\min }}, R_{L-I_{n o m}}$ and $R_{L-I_{\max }}$. By tracing the desired charging current on Fig. 9, it can be noted that the range of switching frequency permitted in the $B C M$ is $f_{\text {sw } \_B C M}=80 \mathrm{kHz} \sim 140 \mathrm{kHz}$.

The battery voltage vs. the operating switching frequency for the entire range of permitted load resistance is shown in Fig. 10. The enclosed surface within the yellow polygon represents the valid operating points. The PID controller is applicable, as the surface is monotonically decreasing.

The worst-case conditions for the current loop controller design are found next. Fig. 11 shows the open-loop bode 

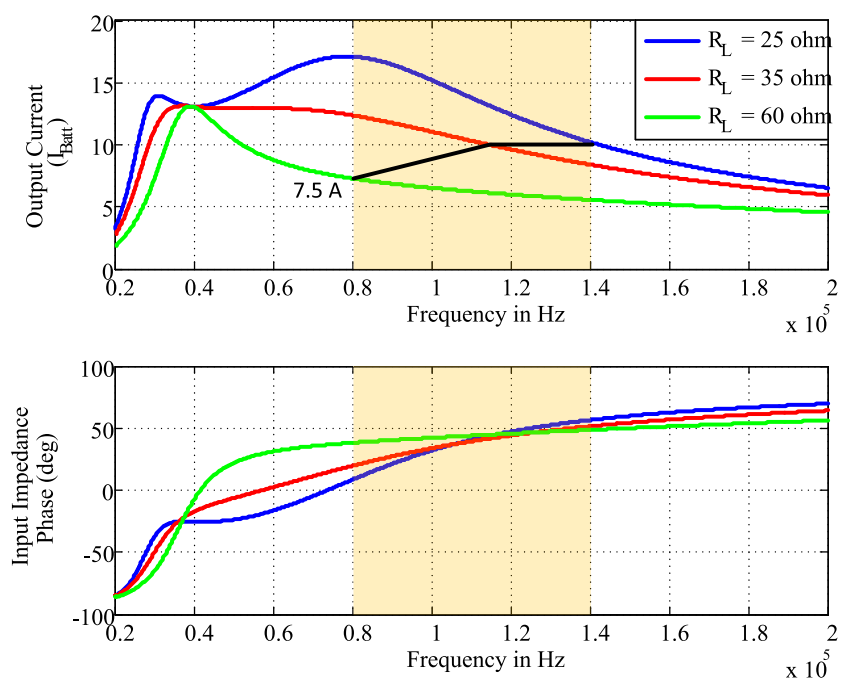

FIGURE 9. Output current vs. switching frequency at different load conditions.

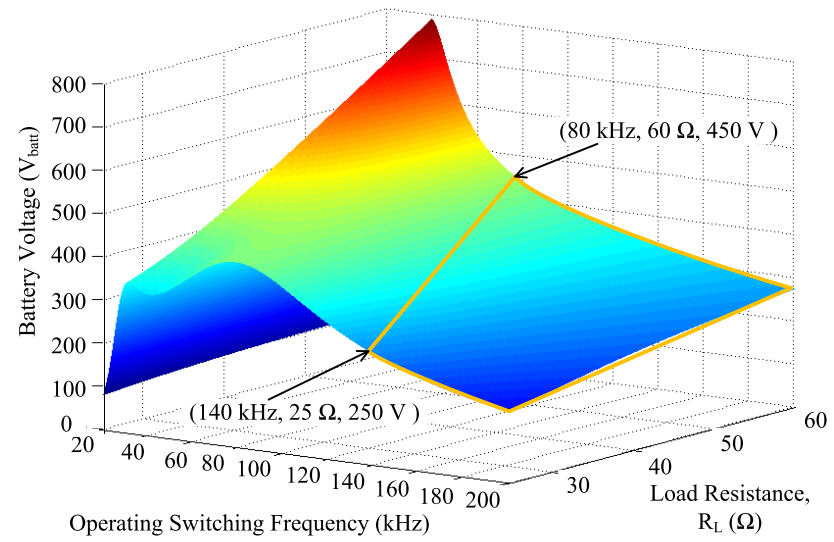

FIGURE 10. Battery voltage vs. switching frequency at different load conditions.

plot for $G_{i f}(s)$ for a $60 \Omega$ load resistance. The operating switching frequency is swept from 80 to $200 \mathrm{kHz}$. It can be noted that the open-loop crossover frequency increases as the converter switching frequency decreases. A maximum open-loop bode-plot crossover frequency is achieved at a switching frequency of $90 \mathrm{kHz}$. Therefore, the worst-case for a fixed load resistance occurs at $90 \mathrm{kHz}$. The openloop control-to-output current, $G_{i f}(s)$ is shown in Fig. 12 for a converter operating at a switching frequency of $90 \mathrm{kHz}$. The output load resistance is varied from $25 \Omega$ to $60 \Omega$. It can be concluded that the crossover frequency of the openloop bode-plot remains nearly constant. It can be concluded from Fig. 9 that the converter will operate at a switching frequency of $90 \mathrm{kHz}$ only for an equivalent load resistance of $35 \Omega$ or more. Therefore, the worst-case for the current loop controller design is when the output load resistance is between $35 \Omega$ and $60 \Omega$.

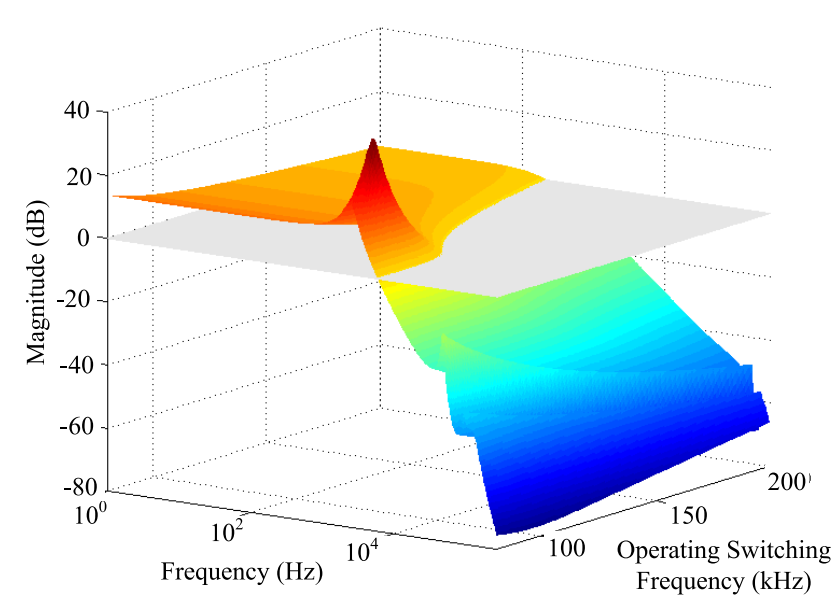

FIGURE 11. Bode-plot for $G_{i f}(s)$ under different switching frequencies.

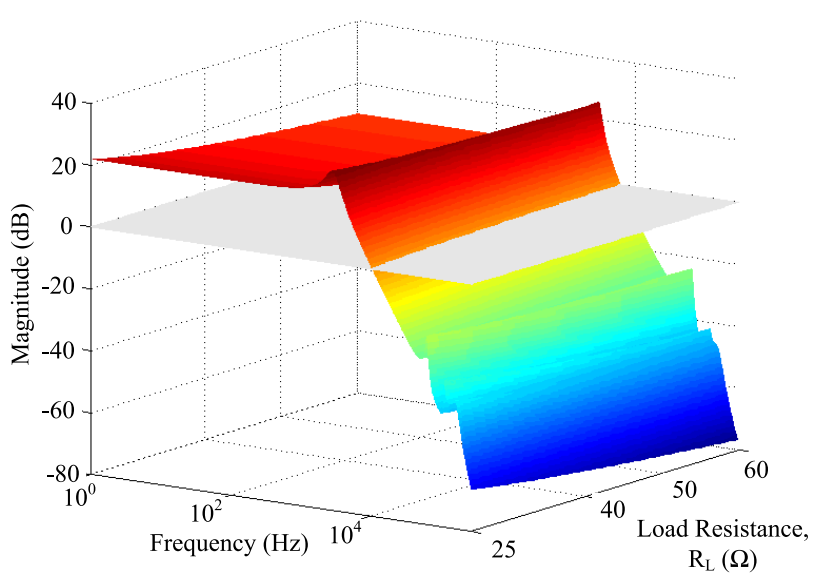

FIGURE 12. Converter $G_{i f}(s)$ Bode plot at $f_{s}=90 \mathrm{kHz}$.

\section{B. WORST-CASE OPERATING CONDITIONS FOR VOLTAGE LOOP CONTROLLER DURING BCM OPERATION}

During constant voltage mode, the converter keeps the battery voltage constant at the reference voltage. In this operating mode, the battery charging current drops to a minimum value, and the equivalent output resistance, $R_{L}$, becomes very large. In this example, a $450 \mathrm{~V}$ battery reference voltage is chosen, and since the minimum charging current is set to $100 \mathrm{~mA}$, then during constant voltage mode, the charging current drops from 7.5 A to $100 \mathrm{~mA}$. So: $R_{L_{-} V}=\frac{V_{\text {Batt }}}{I_{\text {Batt }}}=60 \Omega \sim 4.5 \mathrm{k} \Omega$

The steady-state output battery voltage vs. the operating switching frequency curves are plotted in order to determine the operating frequency range in constant voltage mode as show in Fig. 13 for $R_{L_{-} V \text { min }}$, and at selected larger values using (10) - (11). As can be concluded from Fig. 13, the operating switching frequency range for a converter operating in the constant voltage mode during the $B C M$ is: $f_{s w_{C} V M}=$ $78 \mathrm{kHz} \sim 82 \mathrm{kHz}$. Fig. 13 also shows that PID control can be used to close the voltage loop, since all the curves are monotonically decreasing. 

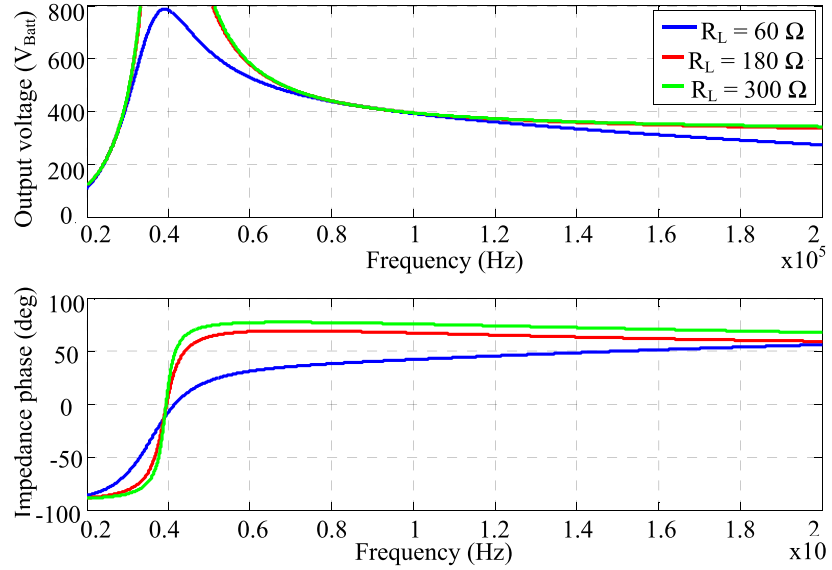

FIGURE 13. BCM operating converter output voltage vs. operating switching frequency under different load conditions.

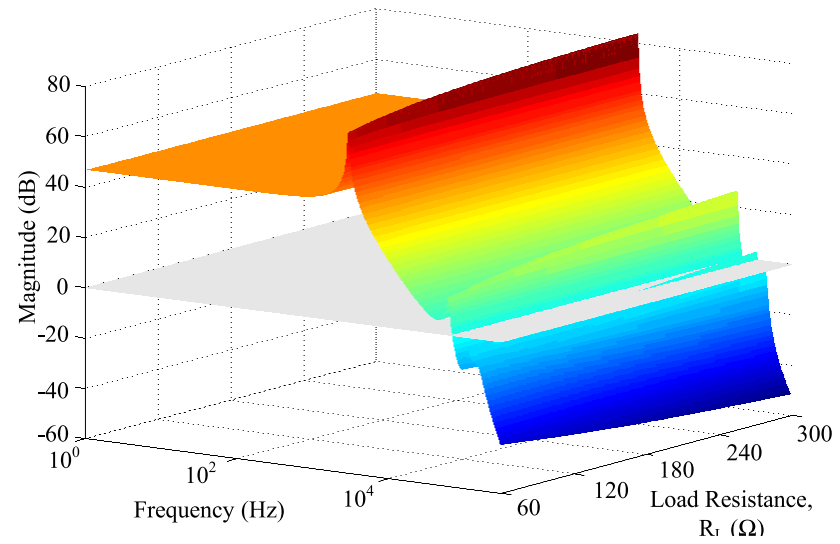

FIGURE 14. $G_{v f}(s)$ open-loop bode-plot with $f_{s}=80 \mathrm{kHz}$.

The control-to-output voltage, $G_{v f}(s)$, bode-plot for a load resistance range of $60 \Omega \sim 300 \Omega$ and switching frequency of $80 \mathrm{kHz}$ is shown in Fig. 14, and is used to find the worstcase operating conditions. It can be seen that the crossover frequency is fixed while the load is changing, however, only the resonant peak increases when $R_{L}$ increases. Keeping the closed loop bandwidth less than the resonant peak frequency, in addition to the existence of the magnetics equivalent resistance, the resonant peak will be considerably attenuated. Therefore, the worst-case operating conditions in the constant voltage mode under BCM operation, is when the output resistance is $60 \Omega$, and the switching frequency is $80 \mathrm{kHz}$.

\section{RM VOLTAGE LOOP CONTROLLER WORST-CASE OPERATING CONDITIONS}

Under RM operation, the DC bus voltage is held constant by converter controls for a wide range of battery input conditions. The converter rms current, $i_{2}$, can become very large for higher output power conditions. To limit this current magnitude, the converter's output power is reduced at lower battery voltages. The proposed converter output power profile vs. battery voltage while operating in $R M$ is shown in Fig. 15.

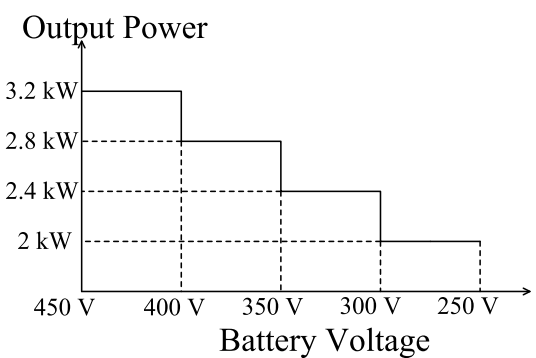

FIGURE 15. $R M$ operating Converter output power vs. the battery voltage.

For the chosen dc bus voltage of $400 \mathrm{~V}$, the equivalent load resistance is: $R_{L}=\frac{V_{D C}^{2}}{P_{o}}=\frac{400^{2}}{3200} \sim \frac{400^{2}}{2000}=50 \Omega \sim 80 \Omega$.

To find the operating frequency range in this mode, the steady-state voltage gain vs. the operating switching frequency is plotted for different load resistances using (10) - (11). Fig. 16 shows these curves and it can be determined that the operating switching frequency range for the converter operating in the $R M$ is: $f_{s w_{C} V M}=$ $45 \mathrm{kHz} \sim 110 \mathrm{kHz}$.
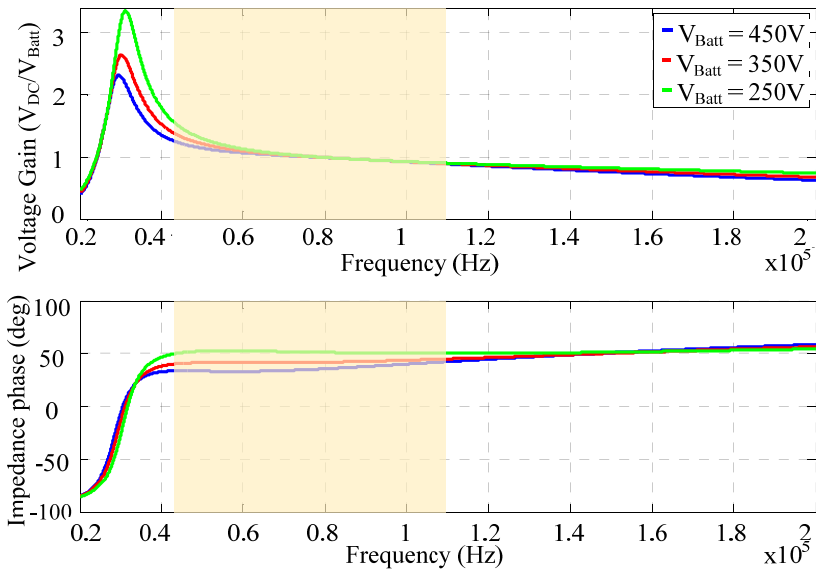

FIGURE 16. BCM operating converter's output voltage vs. operating switching frequency under different load conditions.

The voltage gain vs. the operating switching frequency for the entire range of load resistance is plotted in Fig. 17. The yellow polygon encloses the operating surface. As can be noted from the figure, the enclosed surface decreases monotonically, and a PID controller may be used to close the voltage loop.

The worst-case conditions for the voltage loop controller design is found next. Fig. 18 shows the open-loop control-tooutput voltage, $G_{v f}(s)$, for a $50 \Omega$ load resistance. The operating switching frequency is swept from $45 \mathrm{kHz}$ to $110 \mathrm{kHz}$. It can be observed that the open-loop crossover frequency is constant with the variation of the switching frequency. However, at $90 \mathrm{kHz}$, the open-loop bode-plot shows high resonant peak, therefore it is considered as the worst-case.

Fig. 19 shows the open-loop control-to-output voltage, $G_{v f}(s)$, at a switching frequency of $90 \mathrm{kHz}$. The output 


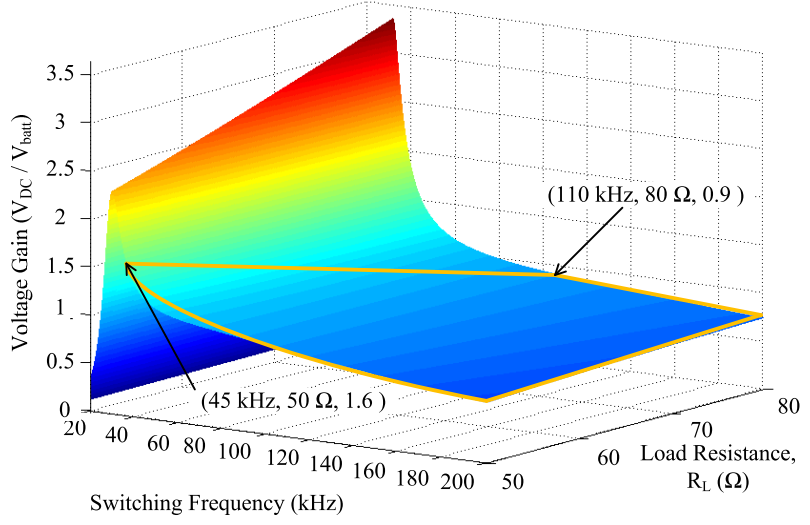

FIGURE 17. BCM battery voltage vs. switching frequency at different load conditions.

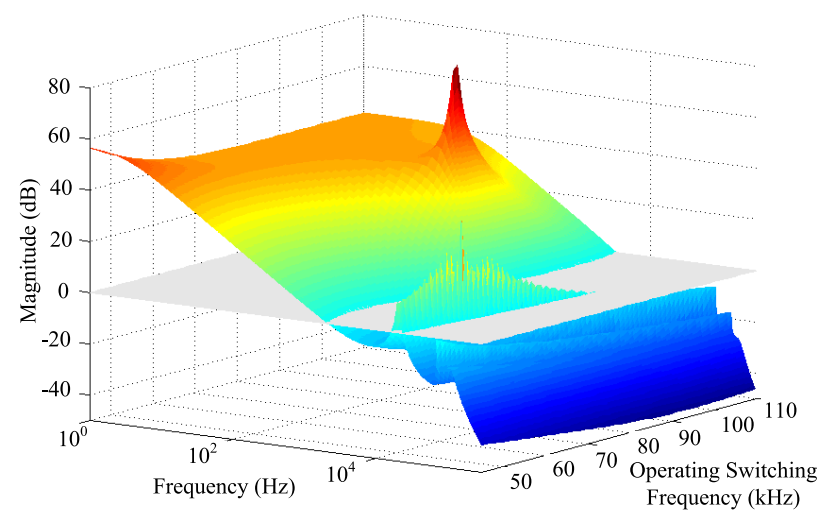

FIGURE 18. $R M$ operating converter open-loop bode-plot for control-to-output voltage, $G_{v f}(s)$, under different switching frequencies.

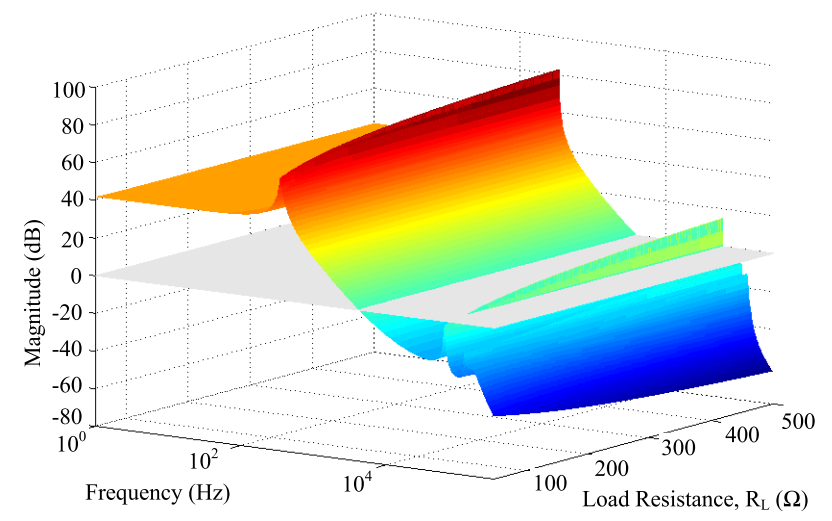

FIGURE 19. $R M$ operating converter open-loop bode-plot $G_{v f}(s)$, at switching frequency of $\mathbf{9 0} \mathbf{k H z}$ under different load conditions.

load resistance is varied from $50 \Omega$ to $500 \Omega$. It can be noted that the crossover frequency of the open-loop bode plot remains constant, and all the plots are exactly alike. The only difference is that the resonant peak gets higher as $R_{L}$ increases. However, the DCR of magnetics' winding and the controller will attenuate this resonant peak considerably if the closed loop bandwidth is much less than the resonant peak frequency. The worst-case operating conditions during constant voltage more RM, are determined to be at output load resistance of $50 \Omega$, and an operating switching frequency of $90 \mathrm{kHz}$.

\section{CONVERTER OPERATION NEAR THE SERIES RESONANT FREQUENCIES}

The efficiency of the power stage of the converter is maximum at the series resonant frequency [28]. Under nominal operating conditions, the converter is designed to operate at this point. However, as shown in the previous section, the worst-case operating conditions for the current and voltage loop controller occur at this frequency, due to the high quality-factor $(\mathrm{Q})$ peak in the open-loop bode. To study this high peak Q in the bode-plots, the zeros and poles of the converter transfer function must be observed when the converter is operating close to the resonant frequencies. The two series resonant frequencies of this converter are;

$$
\begin{aligned}
& f_{\text {ser } 1}=\frac{1}{2 \pi \sqrt{L_{1} C_{1}}}=96.5 \mathrm{kHz} \\
& f_{\text {ser } 2}=\frac{1}{2 \pi \sqrt{L_{2} C_{2}}}=79.58 \mathrm{kHz}
\end{aligned}
$$

The small-signal model in (12) and (13) show that this resonant converter is a $9^{\text {th }}$ order system. This means there are nine poles in each transfer function. But since most of the poles and zeros occur at a very high frequency, they can be ignored.

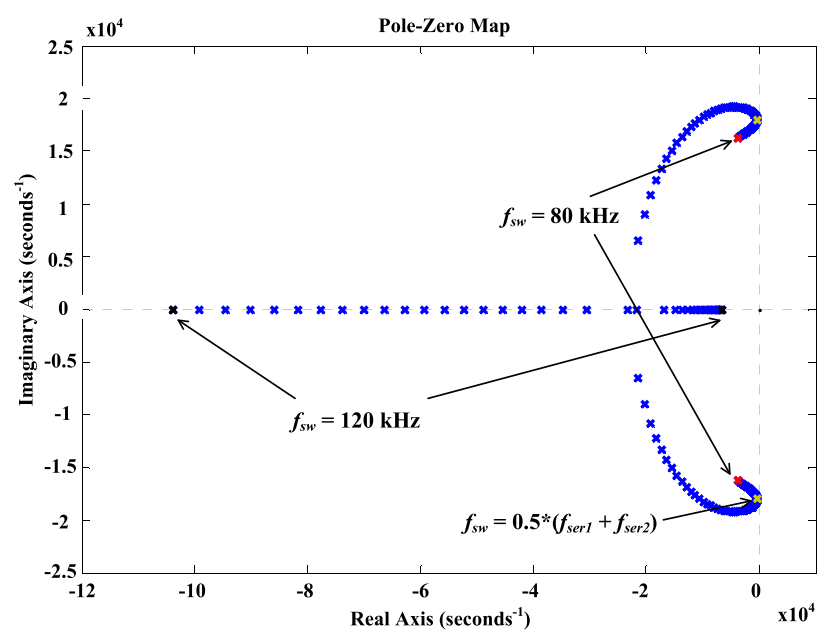

FIGURE 20. Location of the low frequency poles, frequency is varied from $120 \mathrm{kHz}$ to $80 \mathrm{kHz}$.

Fig. 20 shows the dominant poles as the switching frequency is varied from $80 \mathrm{kHz}$ to $120 \mathrm{kHz}$. The dominant poles are on the real axis for higher switching frequencies, and there is no resonant peaking in the bode-plot. As the switching frequency decreases, the two poles are close on the real axis, until they reach the breakaway point. If the switching frequency is further reduced, the two poles break away from the real axis, and move towards the imaginary axis. This is 
when the resonant peaking starts to appear. The damping is minimum (and Q is maximum) at the mid-point between the two resonant frequencies, where the magnitude of the resonant peak is maximum. A yellow cross in Fig. 20 represents this point.

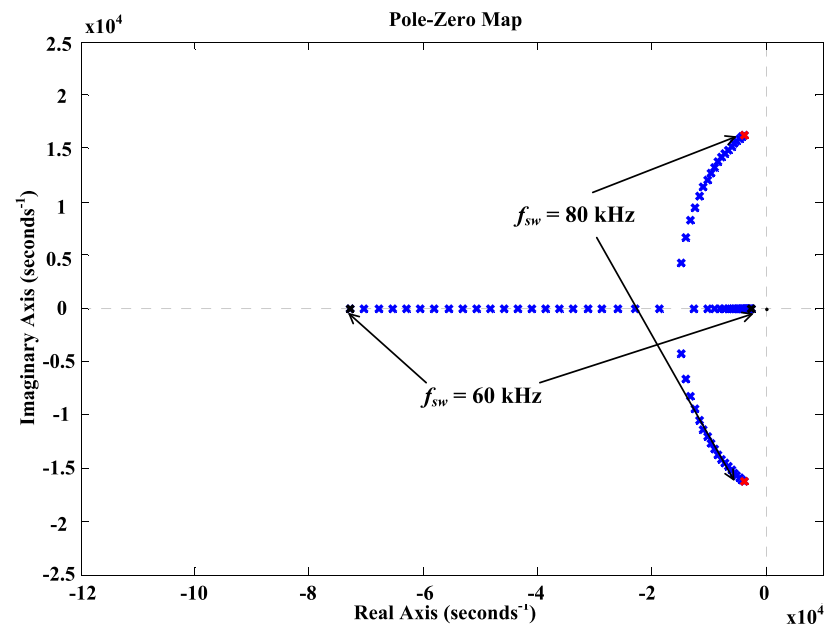

FIGURE 21. Location of the low frequency poles, frequency is varied from $80 \mathrm{kHz}$ to $60 \mathrm{kHz}$.

As can be seen in Fig. 21, if the converter operating frequency is between the two resonant frequencies; the dominant poles are located close to the imaginary axis, which results in resonant peaking in the open-loop bode-plot. However, if the converter switching frequency is reduced, the dominant poles move towards the real axis until they reach the break-in point. If the switching frequency is reduced further, the two dominant poles move away from each other on the real axis, and no resonant peaking occurs in the open-loop bode-plots.

From the above discussion, it can be concluded that no resonant peaking will occur in the open-loop bode plot if the converter operating switching frequency is kept higher than $f_{\text {ser } 1}$ or lower than $f_{\text {ser } 2}$. If the converter operating switching frequency is between the two series resonant frequencies, peaking will occur in the bode-plot due to lower damping and higher Q.

\section{CONTROLLER DESIGN AND EXPERIMENTAL RESULTS}

The worst-case operating conditions were determined in the previous sections for the converter operating in both $B C M$ and $R M$. The controllers will now be designed for these worst-case conditions. The closed loop system block diagram is shown in Fig. 22 where:

$$
\begin{array}{ll}
X & =\text { Output current or voltage to be regulated, } \\
\bar{X} & =\text { Averaged output current or voltage, } \\
X * & =\text { Output current or voltage reference, } \\
H_{x} & =\text { sensor gain, } \\
G_{L P F}(s) & =\text { Low-pass filter implemented the hardware, } \\
H_{A D C} & =\text { Analog-to-digital converter (ADC) gain, }
\end{array}
$$

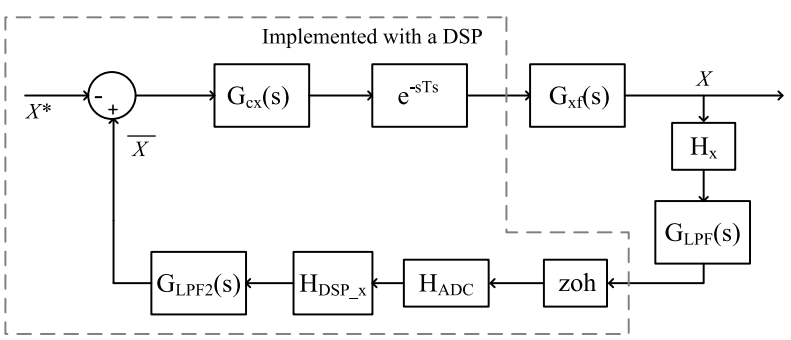

FIGURE 22. Closed-loop system block diagram.

$H_{D S P_{-} x}=$ Digital Signal Processor (DSP) gain,

$G_{L P F 2}(s)=$ Low-pass filter implemented in DSP,

$G_{c x}(s) \quad=$ Designed controller,

$e^{-s T s} \quad=$ Single sampling period delay

The loop-gain of the closed-loop system is,

$$
\begin{aligned}
& T_{x}(s) \\
& \quad=H_{x} G_{x f}(s) G_{L P F}(s) H_{A D C} H_{D S P \_i} G_{L P F 2}(s) G_{C X}(s) e^{-s T s}
\end{aligned}
$$

The chosen DSP gain ensures that the product of all gains is equal to unity, i.e. $H_{x} \cdot H_{D S P_{x}} \cdot H_{A D C}=1$. So, the loop gain becomes,

$T_{x}(s)=G_{x f}(s) \cdot G_{L P F}(s) \cdot G_{L P F 2}(s) \cdot G_{c x}(s) \cdot e^{-s T s}$

The hardware implemented low-pass filter is a sallen-key $2^{\text {nd }}$ order filter. The cut-off frequency is $10 \mathrm{kHz}$. The transfer function $\mathrm{t}$ is:

$$
G_{L P F}(s)=\frac{1}{1+\frac{s}{2 \pi \times 10000}+\left(\frac{s}{2 \pi \times 10000}\right)^{2}}
$$

And, the DSP implemented low-pass filter is,

$$
G_{L P F 2}(s)=\frac{1}{1+\frac{s}{2 \pi \times 1000}}
$$

A Texas Instruments TMS320F28335 DSP is used for control implementation. The sampling frequency is $30 \mathrm{kHz}$, and a $33.33 \mu$ s delay is added in the loop.

$$
e^{-s T s}=\frac{1-\frac{T_{s}}{2} s+\frac{T_{s}^{2}}{12} s^{2}}{1+\frac{T_{s}}{2} s+\frac{T_{s}^{2}}{12} s^{2}}
$$

A 5kW BK Precision 8526 programmable electronic load is used for testing. The programmable load is configured as a battery, where the voltage is varied from $250 \mathrm{~V}$ to $450 \mathrm{~V}$ for $\mathrm{BCM}$ testing. And configured as a current source that varies from $0.1 \mathrm{~A}$ to $8.5 \mathrm{~A}$ to emulate the ac-dc stage for RM testing.

The loop-gain of the converter operating in the constant current mode in the $B C M$ is:

$$
T_{i_{-} B C M}(s)=G_{i f}(s) \cdot G_{L P F}(s) \cdot G_{L P F 2}(s) \cdot G_{c i}(s) \cdot e^{-s T s}
$$


The current loop bandwidth is $515 \mathrm{~Hz}$, with a phase margin of $52.8^{\circ}$ at the worst-case operating conditions.

$$
G_{c i}(s)=\frac{10}{s}
$$

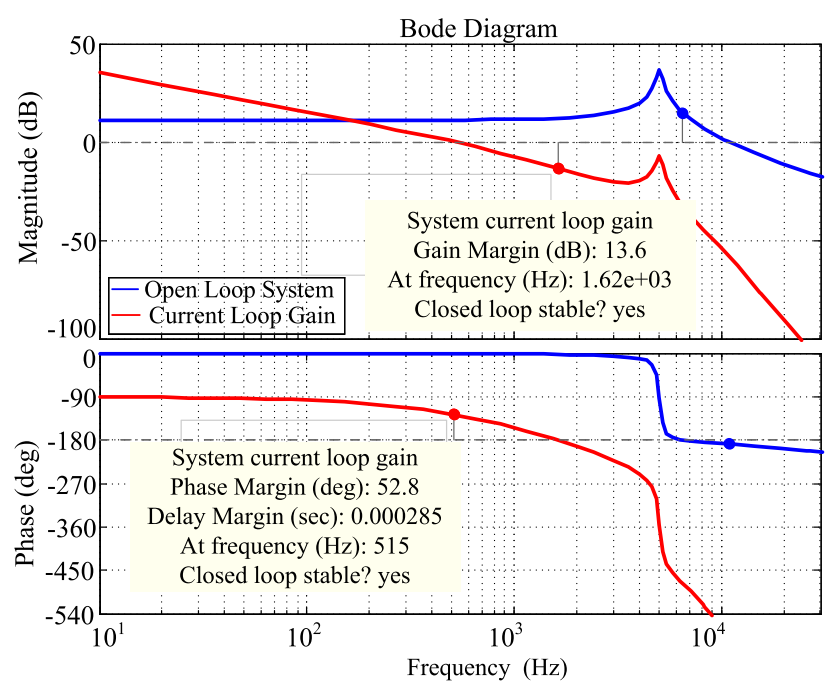

FIGURE 23. Worst-case open-Loop bode-plot and loop gain for BCM operating converter in the constant current mode.

The worst-case open-loop bode-plot and the closed-loop current gain are shown in Fig. 23. A step change to the output battery voltage from $250 \mathrm{~V}$ up to $325 \mathrm{~V}$ and back down to $250 \mathrm{~V}$ was applied to check the closed-loop system stability. The system is stable, with minimal overshoot or undershoot for both step increase and decrease in the battery voltage as shown in Figs. 24 and 25.

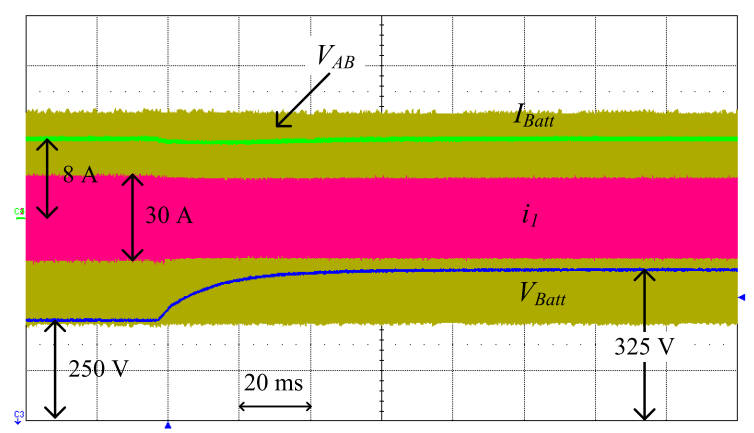

FIGURE 24. Battery voltage step change from $250 \mathrm{~V}$ to $325 \mathrm{~V}$ for $B C M$ constant current mode.

The loop-gain of the converter operating in the constant voltage mode in the $B C M$ is,

$$
T_{v_{-} B C M}(s)=G_{v f}(s) \cdot G_{L P F}(s) \cdot G_{L P F 2}(s) \cdot G_{c v}(s) \cdot e^{-s T s}
$$

The controller is designed with a $103 \mathrm{~Hz}$ bandwidth, and a phase margin of $82.2^{\circ}$.

$$
G_{c v}(s)=\frac{0.3}{s}
$$

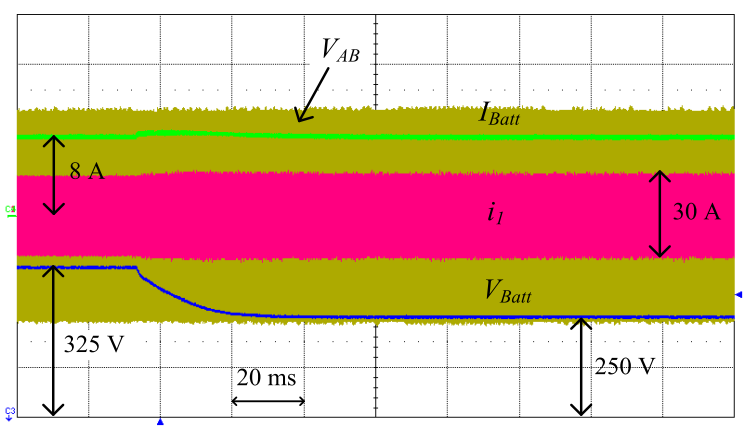

FIGURE 25. Battery voltage step change from $325 \mathrm{~V}$ to $250 \mathrm{~V}$ for $B C M$ constant current mode.

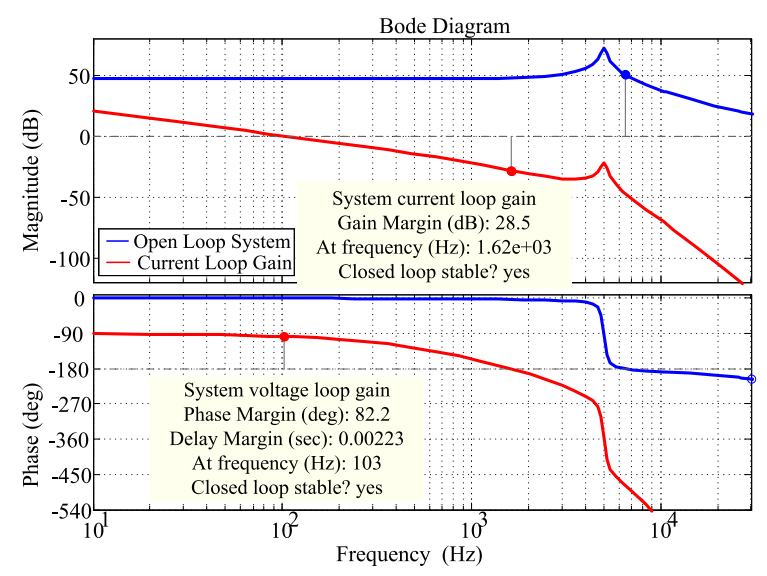

FIGURE 26. The worst-case open-Loop bode-plot and loop gain for converter operating in the constant voltage mode in the BCM.

The worst-case open-loop bode-plot and the closed-loop current gain are shown in Fig. 26. A step change to the output voltage reference from $315 \mathrm{~V}$ to $420 \mathrm{~V}$ and back to $315 \mathrm{~V}$ was applied with a resistive load of $57 \Omega$ to check the system stability. The system is stable, with no overshoot or undershoot for both step changes in the reference voltage as shown in Fig. 27 and Fig. 28.

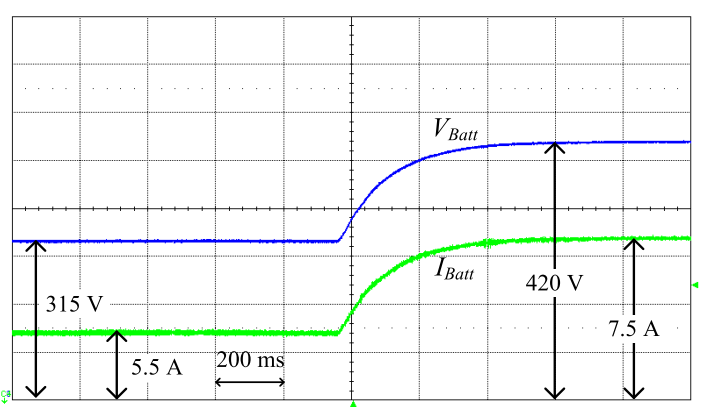

FIGURE 27. Battery voltage step change from $315 \mathrm{~V}$ to $420 \mathrm{~V}$ for $B C M$ constant current mode converter with $R_{L}=57 \Omega$.

The loop-gain of the converter operating in the constant voltage mode in the $R M$ is,

$$
T_{v_{-} R M}(s)=G_{v f}(s) \cdot G_{L P F}(s) \cdot G_{L P F 2}(s) \cdot G_{C v}(s) \cdot e^{-s T s}
$$




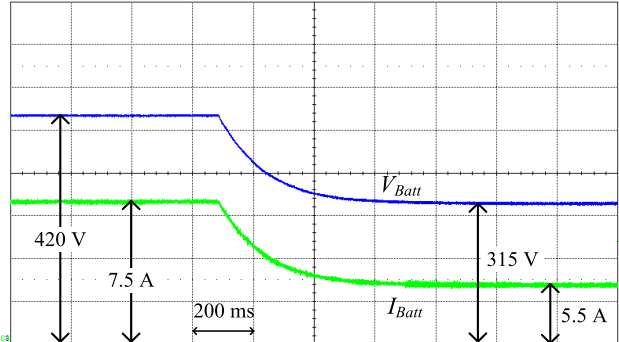

FIGURE 28. Battery voltage step change from $420 \mathrm{~V}$ to $315 \mathrm{~V}$ for $B C M$ constant current mode converter with $R_{L}=57 \Omega$.

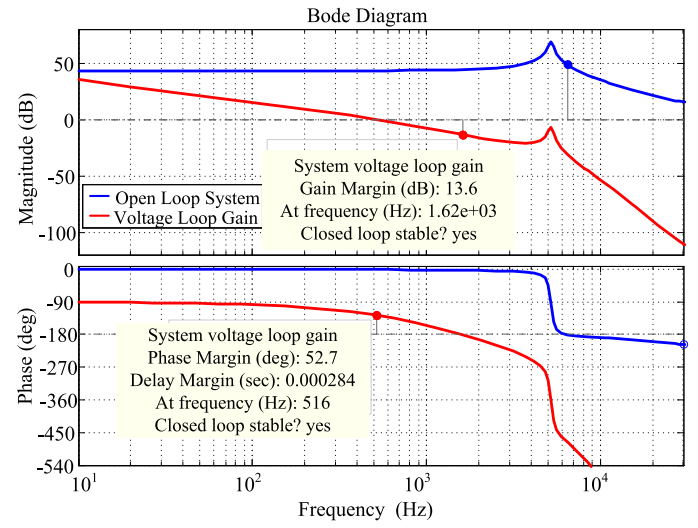

FIGURE 29. Worst-case open-Loop bode-plot and loop gain for RM operating converter in the constant voltage mode.

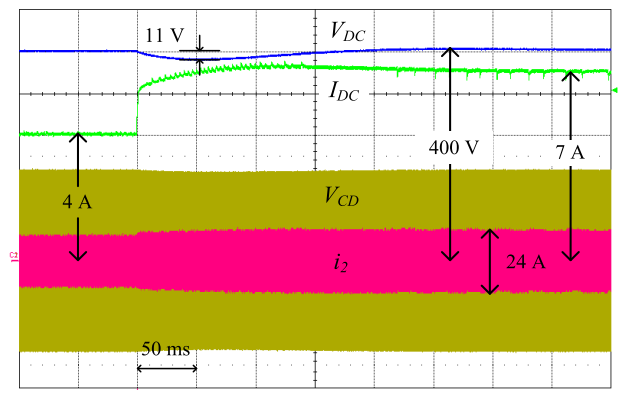

FIGURE 30. Step change in the dc bus current from $4 \mathrm{~A}$ to $7 \mathrm{~A}$ for $R M$ operating converter in the constant voltage mode.

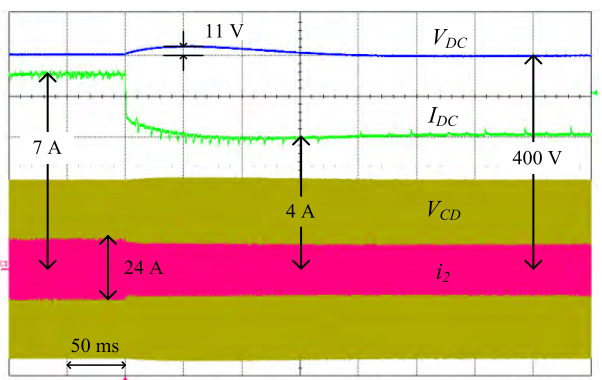

FIGURE 31. Step change in the dc bus current from $7 \mathrm{~A}$ to $4 \mathrm{~A}$ for $\mathrm{RM}$ operating converter in the constant voltage mode.

The following controller is designed for a $516 \mathrm{~Hz}$ bandwidth, and a phase margin of $52.7^{\circ}$.

$$
G_{c v}(s)=\frac{2.5}{s}
$$

The worst-case open-loop bode-plot and the closed-loop current gain are shown in Fig. 29. A step change to the output current reference from $4 \mathrm{~A}$ to $7 \mathrm{~A}$ and back to $4 \mathrm{~A}$ was applied to check the system stability. The system is stable, with nearly no overshoot or undershoot for the step change in the reference current as shown in Fig. 30 and Fig. 31.

\section{CONCLUSIONS}

The $C L L L C$-type resonant converter is a promising topology that gives high conversion efficiency backed by soft switching capability on the primary and secondary sides of the isolation transformer. Due to the variable dynamics at different loading conditions, the stability of the governing controllers becomes an issue, and a globally stable controller for all working scenarios becomes important. The definition of worst case scenario conditions was presented in this manuscript and a controller design methodology accordingly was devised. The stability margins for all working conditions was graphically presented to firm the design outputs.

Controllers' design in both BCM and RM modes were presented and verified by both simulation and experimental results. The results showed that the designed controllers can account to all operating conditions and the analysis provided priori introduces thorough insight on the dynamic modeling of the CLLLC-type resonant converters.

As future extension of this work, it might be suggested to implement dynamic controllers to maximize the bandwidth at all operating conditions. Scheduled gain controllers are examples of such controllers that might be adapted.

\section{APPENDIX}

See Table 2 .

\begin{tabular}{|c|c|c|}
\hline$K_{1}=\frac{4\left(I_{2 c}\right)^{2} \cdot V_{C f}}{\pi L_{e q m} I_{p k}{ }^{3}}$ & $K_{2}=\frac{4 I_{2 s} I_{2 c} \cdot V_{C f}}{\pi L_{e q m} I_{p k}{ }^{3}}$ & $K_{3}=\frac{4 I_{2 s}}{\pi L_{e q m} I_{p k}}$ \\
\hline$K_{4}=\frac{4}{\pi L_{e q 2}} \sin \left(\frac{\pi}{2} D\right)$ & $K_{5}=\frac{2 V_{g}}{L_{e q 2}} \cos \left(\frac{\pi}{2} D\right)$ & $K_{6}=\frac{4\left(I_{2 c}\right)^{2} \cdot V_{C f}}{\pi L_{e q 1} I_{p k}{ }^{3}}$ \\
\hline$K_{7}=\frac{4 I_{2 s} I_{2 c} \cdot V_{C f}}{\pi L_{e q 1} I_{p k}{ }^{3}}$ & $K_{8}=\frac{4 I_{2 s}}{\pi L_{e q 1} I_{p k}}$ & $K_{9}=\frac{4}{\pi L_{e q m}} \sin \left(\frac{\pi}{2} D\right)$ \\
\hline$K_{10}=\frac{2 V_{g}}{L_{e q m}} \cos \left(\frac{\pi}{2} D\right)$ & $K_{11}=\frac{4 I_{2 s} I_{2 c} \cdot V_{C f}}{\pi L_{e q m} I_{p k}{ }^{3}}$ & $K_{12}=\frac{4\left(I_{2 s}\right)^{2} \cdot V_{C f}}{\pi L_{e q m} I_{p k}{ }^{3}}$ \\
\hline$K_{13}=\frac{4 I_{2 c}}{\pi L_{e q m} I_{p k}}$ & $K_{14}=\frac{4 I_{2 s} I_{2 c} \cdot V_{C f}}{\pi L_{e q 1} I_{p k}{ }^{3}}$ & $K_{15}=\frac{4\left(I_{2 s}\right)^{2} \cdot V_{C f}}{\pi L_{e q 1} I_{p k}{ }^{3}}$ \\
\hline$K_{16}=\frac{4 I_{2 c}}{\pi L_{e q 1} I_{p k}}$ & $K_{17}=\frac{2}{\pi C_{f}} \frac{R_{L}}{R_{L}+R_{c}} \frac{I_{2 s}}{I_{p k}}$ & $K_{18}=\frac{2}{\pi C_{f}} \frac{R_{L}}{R_{L}+R_{c}} \frac{I_{2 c}}{I_{p k}}$ \\
\hline$K_{19}=\frac{1}{C_{f}} \frac{1}{R_{L}+R_{c}}$ & $K_{20}=\frac{2}{\pi} \frac{R_{c} R_{L}}{R_{L}+R_{c}} \frac{I_{2 s}}{I_{p k}}$ & $K_{21}=\frac{2}{\pi} \frac{R_{c} R_{L}}{R_{L}+R_{c}} \frac{I_{2 c}}{I_{p k}}$ \\
\hline$K_{22}=\frac{R_{L}}{R_{L}+R_{c}}$ & \\
\hline
\end{tabular}

\section{REFERENCES}

[1] A. Emadi, L. J. Young, and K. Rajashekara, "Power electronics and motor drives in electric, hybrid electric, and plug-in hybrid electric vehicles," IEEE Trans. Ind. Electron., vol. 55, no. 6, pp. 2237-2245, Jun. 2008. 
[2] H. Zhang, J. Wang, and Y.-Y. Wang, "Optimal dosing and sizing optimization for a ground-vehicle diesel-engine two-cell selective catalytic reduction system," IEEE Trans. Veh. Technol., vol. 65, no. 6, pp. 4740-4751, Jun. 2016.

[3] H. Ma et al., "Model-based multiobjective evolutionary algorithm optimization for HCCI engines," IEEE Trans. Veh. Technol., vol. 64, no. 9, pp. 4326-4331, Sep. 2015.

[4] X. Hu, H. Wang, and X. Tang, "Cyber-physical control for energy-saving vehicle following with connectivity," IEEE Trans. Ind. Electron., vol. 64 , no. 11, pp. 8578-8587, Nov. 2017.

[5] L. Zhang, X. Hu, Z. Wang, F. Sun, J. Deng, and D. G. Dorrell, "Multiobjective optimal sizing of hybrid energy storage system for electric vehicles,' IEEE Trans. Veh. Technol., vol. 67, no. 2, pp. 1027-1035, Feb. 2018.

[6] A. Khaligh and Z. Li, "Battery, ultracapacitor, fuel cell, and hybrid energy storage systems for electric, hybrid electric, fuel cell, and plug-in hybrid electric vehicles: State of the art," IEEE Trans. Veh. Technol., vol. 59, no. 6 , pp. 2806-2814, Jul. 2010.

[7] X. Hu, L. Johannesson, N. Murgovski, and B. Egardt, "Longevityconscious dimensioning and power management of the hybrid energy storage system in a fuel cell hybrid electric bus," Appl. Energy, vol. 137, pp. 913-924, Jan. 2015.

[8] M.-E. Choi, J.-S. Lee, and S.-W. Seo, "Real-time optimization for power management systems of a battery/supercapacitor hybrid energy storage system in electric vehicles," IEEE Trans. Veh. Technol., vol. 63, no. 8, pp. 3600-3611, Oct. 2014.

[9] Z. Song, H. Hofmann, J. Li, J. Hou, X. Han, and M. Ouyang, "Energy management strategies comparison for electric vehicles with hybrid energy storage system," Appl. Energy, vol. 134, pp. 321-331, Dec. 2014

[10] J. Cao and A. Emadi, "A new battery/ultracapacitor hybrid energy storage system for electric, hybrid, and plug-in hybrid electric vehicles," IEEE Trans. Power Electron., vol. 27, no. 1, pp. 122-132, Jan. 2012.

[11] M. Shahverdi, M. S. Mazzola, Q. Grice, and M. Doude, "Pareto front of energy storage size and series hev fuel economy using bandwidthbased control strategy," IEEE Trans. Transport. Electrific., vol. 2, no. 1, pp. 36-51, Mar. 2016.

[12] H. Wang, S. Dusmez, and A. Khaligh, "Design and analysis of a full-bridge LLC-based PEV charger optimized for wide battery voltage range," IEEE Trans. Veh. Technol., vol. 63, no. 4, pp. 1603-1613, Apr. 2014.

[13] L. Xue, Z. Shen, D. Boroyevich, P. Mattavelli, and D. Diaz, "Dual active bridge-based battery charger for plug-in hybrid electric vehicle with charging current containing low frequency ripple," IEEE Trans. Power Electron., vol. 30, no. 12, pp. 7299-7307, Dec. 2015.

[14] I.-O. Lee, "Hybrid PWM-resonant converter for electric vehicle onboard battery chargers," IEEE Trans. Power Electron., vol. 31, no. 5, pp. 3639-3649, May 2015.

[15] B. Gu, C. Y. Lin, B. Chen, J. Dominic, and J. S. Lai, "Zero-voltageswitching PWM resonant full-bridge converter with minimized circulating losses and minimal voltage stresses of bridge rectifiers for electric vehicle battery chargers," IEEE Trans. Power Electron., vol. 28, no. 10, pp. 4657-4667, Oct. 2013.

[16] C. Liu et al., "High-efficiency hybrid full-bridge-half-bridge converter with shared zvs lagging leg and dual outputs in series," IEEE Trans. Power Electron., vol. 28, no. 2, pp. 849-861, Feb. 2013.

[17] B. Gu, J.-S. Lai, N. Kees, and C. Zheng, "Hybrid-switching full-bridge DC-DC converter with minimal voltage stress of bridge rectifier, reduced circulating losses, and filter requirement for electric vehicle battery chargers," IEEE Trans. Power Electron., vol. 28, no. 3, pp. 1132-1144, Mar. 2013.

[18] N. H. Kutkut, "A full bridge LCL resonant battery charger for an EV conductive coupler," in Proc. 29th Annu. IEEE Power Electron. Specialists Conf. (PESC), vol. 2. May 1998, pp. 2069-2075.

[19] J. G. Hayes, "Battery charging systems for electric vehicles," in Proc. IEE Colloq. Elect. Vehicles-Technol. Roadmap Future, 1998, p. 4.

[20] A. Khaligh and S. Dusmez, "Comprehensive topological analysis of conductive and inductive charging solutions for plug-in electric vehicles,' IEEE Trans. Veh. Technol., vol. 61, no. 8, pp. 3475-3489, Oct. 2012.

[21] N. Liu and T. G. Habetler, "Design of a universal inductive charger for multiple electric vehicle models," IEEE Trans. Power Electron., vol. 30, no. 11, pp. 6378-6390, Nov. 2015.

[22] J. Deng, W. Li, T. D. Nguyen, S. Li, and C. C. Mi, "Compact and efficient bipolar coupler for wireless power chargers: Design and analysis," IEEE Trans. Power Electron., vol. 30, no. 11, pp. 6130-6140, Nov. 2015
[23] W. Zhang, J. C. White, A. M. Abraham, and C. C. Mi, "Loosely coupled transformer structure and interoperability study for EV wireless charging systems," IEEE Trans. Power Electron., vol. 30, no. 11, pp. 6356-6367, Nov. 2015.

[24] W. Zhang, S.-C. Wong, C. K. Tse, and Q. Chen, "Design for efficiency optimization and voltage controllability of series-series compensated inductive power transfer systems," IEEE Trans. Power Electron., vol. 29, no. 1, pp. 191-200, Jan. 2014.

[25] Z. U. Zahid et al., "Design and control of a single-stage large air-gapped transformer isolated battery charger for wide-range output voltage for EV applications," in Proc. IEEE Energy Convers. Congr. Exposit. (ECCE), Sep. 2013, pp. 5481-5487.

[26] D. J. Thrimawithana, U. K. Madawala, and M. Neath, "A synchronization technique for bidirectional IPT systems," IEEE Trans. Ind. Electron., vol. 60, no. 1, pp. 301-309, Jan. 2012

[27] D. J. Thrimawithana and U. K. Madawala, "A generalized steady-state model for bidirectional IPT systems," IEEE Trans. Power Electron., vol. 28 , no. 10, pp. 4681-4689, Oct. 2013

[28] Z. U. Zahid, Z. Dalala, and J.-S. J. Lai, "Design and control of bidirectional resonant converter for Vehicle-to-Grid (V2G) applications," in Proc. 40th Annu. Conf. IEEE Ind. Electron. Soc. (IECON), Oct./Nov. 2014, pp. 1370-1376.

[29] R. Middlebrook and S. Cuk, "A general unified approach to modelling switching-converter power stages," in Proc. IEEE Power Electron. Spec. Conf., Jun. 1976, pp. 18-34.

[30] S. Cuk and R. D. Middlebrook, "A general unified approach to modelling switching DC-to-DC converters in discontinuous conduction mode," in Proc. IEEE Power Electron. Spec. Conf., Jun. 1977, pp. 36-57.

[31] V. Vorperian, "Simplified analysis of PWM converters using model of PWM switch. II. Discontinuous conduction mode," IEEE Trans. Aerosp. Electron. Syst., vol. 26, no. 3, pp. 497-505, May 1990.

[32] V. Vorperian, "Simplified analysis of PWM converters using model of PWM switch. Continuous conduction mode," IEEE Trans. Aerosp. Electron. Syst., vol. 26, no. 3, pp. 490-496, May 1990.

[33] G. Di Capua, S. A. Shirsavar, M. A. Hallworth, and N. Femia, "An enhanced model for small-signal analysis of the phase-shifted full-bridge converter," IEEE Trans. Power Electron., vol. 30, no. 3, pp. 1567-1576, Mar. 2015.

[34] A. F. Witulski, A. F. Hernandez, and R. W. Erickson, "Small signal equivalent circuit modeling of resonant converters," IEEE Trans. Power Electron., vol. 6, no. 1, pp. 11-27, Jan. 1991.

[35] G. J. J. V. Zyl, "A novel frequency-domain small-signal analysis of resonant power converters," IEEE Trans. Circuits Syst. I, Reg. Papers, vol. 51, no. 7, pp. 1379-1384, Jul. 2004.

[36] V. Vorperian, "Approximate small-signal analysis of the series and the parallel resonant converters," IEEE Trans. Power Electron., vol. 4, no. 1, pp. 15-24, Jan. 1989.

[37] R. J. King and T. A. Stuart, "Small-signal model for the series resonant converter," IEEE Trans. Aerosp. Electron. Syst., vol. AES-21, no. 3, pp. 301-319, May 1985.

[38] Y. Yin, R. Zane, R. Erickson, and J. Glaser, "Direct modeling of envelope dynamics in resonant inverters," in Proc. IEEE 34th Annu. Power Electron. Spec. Conf. (PESC), vol. 3. Jun. 2003, pp. 1313-1318.

[39] V. Vorperian, "High-Q approximation in the small-signal analysis of resonant converters," in Proc. IEEE Power Electron. Spec. Conf., Jun. 1985, pp. 707-715.

[40] V. Vorperian and S. Cuk, "Small signal analysis of resonant converters," in Proc. IEEE Power Electron. Spec. Conf., Jun. 1983, pp. 269-282.

[41] E. X. Yang, F. C. Lee, and M. M. Jovanovic, "Small-signal modeling of series and parallel resonant converters," in Proc. 7th Annu. Conf. Appl. Power Electron. Conf. Expo. (APEC), Feb. 1992, pp. 785-792.

[42] S. R. Sanders, J. M. Noworolski, X. Z. Liu, and G. C. Verghese, "Generalized averaging method for power conversion circuits," IEEE Trans. Power Electron., vol. 6, no. 2, pp. 251-259, Apr. 1991.

[43] A. P. Hu, "Modeling a contactless power supply using GSSA method," in Proc. IEEE Int. Conf. Ind. Technol. (ICIT), Feb. 2009, pp. 1-6.

[44] S. Zong, H. Luo, W. Li, X. He, and C. Xia, "Theoretical evaluation of stability improvement brought by resonant current loop for paralleled LLC converters," IEEE Trans. Ind. Electron., vol. 62, no. 7, pp. 4170-4180, Jul. 2015.

[45] B. Yang, F. C. Lee, A. J. Zhang, and G. Huang, "LLC resonant converter for front end DC/DC conversion," in Proc. 17th Annu. IEEE Appl. Power Electron. Conf. Expo. (APEC), vol. 2. Mar. 2002, pp. 1108-1112. 
[46] E. X. Yang, F. C. Lee, and M. M. Jovanovic, "Small-signal modeling of LCC resonant converter," in Proc. 23rd Annu. IEEE Power Electron. Spec. Conf. (PESC), vol. 2. Jun./Jul. 1992, pp. 941-948.

[47] Z. U. Zahid et al., "Modeling and control of series-series compensated inductive power transfer system," IEEE J. Emerg. Sel. Topics Power Electron., vol. 3, no. 1, pp. 111-123, Mar. 2015.

[48] C. H. Chang, C. A. Cheng, and H. L. Cheng, "Modeling and design of the LLC resonant converter used as a solar-array simulator," IEEE J. Emerg. Sel. Topics Power Electron., vol. 2, no. 4, pp. 833-841, Dec. 2014.

[49] B. Yang, F. C. Lee, and M. Jovanovic, "Small-signal analysis for LLC resonant converter,' in Proc. CPES Seminar, 2003, pp. 144-149.

[50] Z. M. Dalala, Z. U. Zahid, and J. S. J. Lai, "Modeling and controller design of a bidirectional resonant converter battery charger," in Proc. Asian Conf. Energy, Power Transp. Electrific. (ACEPT), Oct. 2016, pp. 1-7.

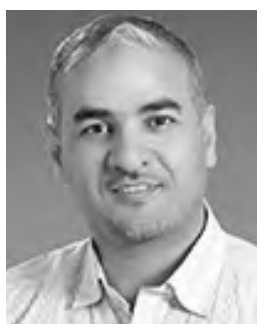

ZAKARIYA M. DALALA (S'13-M'14) received the B.S. degree from the Jordan University of Science and Technology, Irbid, Jordan, the M.S degree from the University of Jordan, Amman, Jordan, and the Ph.D. degree from Virginia Tech, Blacksburg, VA, USA, in 2005, 2009, and 2014 respectively, all in electrical engineering. From 2010 to 2014, he was a Graduate Research Assistant with the Future Energy Electronics Center, Virginia Tech. He is currently with the Energy Engineering Department, German Jordanian University, as an Assistant Professor. His research interests include energy efficient conversion, power electronic converters design and control for renewable energy systems, digital control and optimization, microgrid applications, and high-performance motor drives.

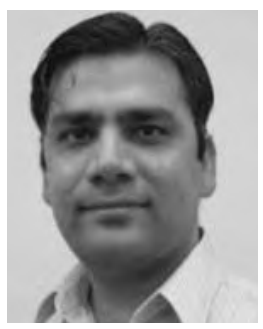

ZAKA ULLAH ZAHID received the B.S. degree in electrical and electronics engineering from the NWFP University of Engineering and Technology (UET), Peshawar, Pakistan, the M.S. degree in electrical engineering from George Washington University, Washington, DC, USA, and the Ph.D. degree from Virginia Tech, Blacksburg, VA, USA, in 2007, 2009, and 2015, respectively. He was a Graduate Research Assistant with the Future Energy Electronics Center, Virginia Tech, from 2010 to 2015 . His research interests include the design and control of transformer isolated $\mathrm{dc}-\mathrm{dc}$ converters for battery charging and vehicle-to-grid applications, power electronics for energy conversion, and control theory applications.

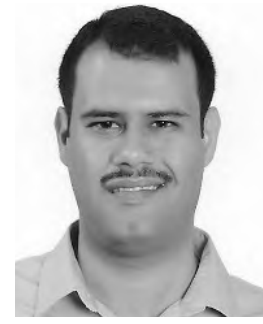

OSAMA S. SAADEH (S'02-M'10) received the B.Sc. degree in electrical engineering from the Jordan University of Science and Technology (JUST), Jordan, in 2004, and the M.Sc. and Ph.D degrees in electrical engineering from the University of Arkansas, USA, in 2007 and 2011, respectively. He was with the Department of Electrical Engineering, JUST, from 2011 to 2017. He was the Director of the Energy Center, JUST, from 2014 to 2016. He is currently with the Energy Engineering Department, German Jordan University. His research interests include power electronics with emphasis on modeling and simulation, power semiconductor devices, widebandgap power electronics, the applications of power electronics in power systems, renewable energy interfaces, and power system protection and quality. He is a member of Eta Kappa $\mathrm{Nu}$.

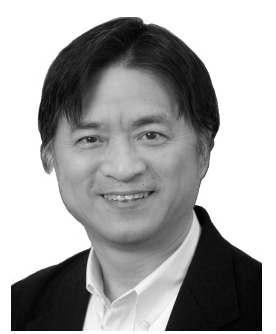

JIH-SHENG (JASON) LAI (S'85-M'89-SM'93F'07) received the M.S. and Ph.D. degrees in electrical engineering from the University of Tennessee, Knoxville, TN, USA, in 1985 and 1989, respectively. In 1989, he joined the Power Electronics Applications Center, Electric Power Research Institute (EPRI), where he managed EPRI-sponsored power electronics research projects. In 1993, he then joined the Oak Ridge National Laboratory as a Power Electronics Lead Scientist, where he initiated the high-power electronics program and developed several novel high-power converters, including multilevel converters and soft-switching inverters. In 1996, he joined the Virginia Polytechnic Institute and State University. He is currently the James S. Tucker Professor with the Electrical and Computer Engineering Department and the Director of the Future Energy Electronics Center. He also holds a Visiting Professorship at Nanyang Technological University, Singapore, and National Chiao Tung University, Taiwan. He published over 420 refereed technical papers and two books and received 25 U.S. patents. His main research interests include high-efficiency power electronics conversions for high power and energy applications. He received the Technical Achievement Award in Lockheed Martin Award Night, two Journal Paper Awards, 12 Best Paper Awards from the IEEE sponsored conferences, and the Virginia Tech Dean's Award on Research Excellence. He was a recipient of the 2016 IEEE IAS Gerald Kliman Innovator Award. He led the student teams to win the Top Three Finalist in Google Little Box Challenge in 2016, the Grand Prize Award from International Future Energy Challenge (IFEC) in 2011, and the Grand Prize Award from Texas Instruments Engibous Analog Design Competition in 2009. He is the founding Chair of the 2001 IFEC and the 2016 IEEE Asian Conference on Energy, Power, and Transportation Electrification, the General Chair of the IEEE Workshop on Computers in Power Electronics (COMPEL 2000) and the IEEE Applied Power Electronics Conference and Exposition (APEC 2005). 